\title{
FORMAÇÃO INICIAL PARA A DOCÊNCIA NA EDUCAÇÃO INFANTIL: INDICADORES DA PRODUÇÃO ACADÊMICA
}

\author{
Valdete Côco (UFES)* \\ Maria Nilceia de Andrade Vieira (UFES)** \\ Karina de Fátima Giesen (UFES)***
}

\begin{abstract}
RESUMO
Este texto discute a formação inicial para a docência na Educação Infantil, com o objetivo de analisar indicadores decorrentes de produções acadêmicas recentes sobre a temática. Ancorado em pressupostos teórico-metodológicos bakhtinianos, o presente estudo caracteriza-se por uma abordagem qualitativa de caráter exploratório. Para a produção de dados, optou-se por procedimento de levantamento bibliográfico em periódicos nacionais. A sistematização dos resultados constituiu-se por apuração de dados quantitativos e análise dos enunciados expressos nos artigos selecionados. Essa interlocução evidenciou a relevância da dimensão pessoal na formação para a profissão docente, com destaque para a necessidade de parceria entre docentes da graduação e os estudantes e para a discussão dos desafios vinculados às políticas de reconhecimento e valorização do professor, explicitando a complexidade dos processos de formação docente.
\end{abstract}

Palavras-chave: Formação inicial. Docência. Educação infantil.

\section{ABSTRACT}

\section{INITIAL FORMATION FOR TEACHING IN EARLY CHILDHOOD EDUCATION: INDICATORS OF ACADEMIC PRODUCTION}

This text discusses the initial training for teaching in Early Childhood Education, with the objective of analyzing indicators derived from recent academic productions on the subject. Anchored in Bakhtinian theoretical-methodological assumptions, the present study is characterized by a qualitative exploratory approach. For the production of data, a bibliographic survey procedure was chosen in national journals. The systematization of the results consisted of quantitative data and analysis of the statements expressed

\footnotetext{
* Doutora em Educação pela Universidade Federal Fluminense (UFF). Professora vinculada ao Departamento de Linguagens, Cultura e Educação e ao Programa de Pós-graduação em Educação do Centro de Educação da Universidade Federal do Espírito Santo (UFES). Coordenadora do Grupo de Pesquisa Formação e Atuação de Educadores (GRUFAE). E-mail: valdetecoco@hotmail.com

** Doutoranda em Educação pelo Programa de Pós-graduação em Educação do Centro de Educação da Universidade Federal do Espírito Santo (UFES). Membro do Grupo de Pesquisa Formação e Atuação de Educadores (GRUFAE). Pedagoga na Rede Municipal de Ensino de Vitória. Professora da Faculdade Estácio de Vila Velha. E-mail: nilceia_vilavelha@hotmail.com

*** Mestranda em Educação pelo Programa de Pós-graduação em Educação do Centro de Educação da Universidade Federal do Espírito Santo (UFES). Membro do Grupo de Pesquisa Formação e Atuação de Educadores (GRUFAE). E-mail: karina-giesen@hotmail.com
} 
in the selected articles. This interlocution evidenced the relevance of the personal dimension in the training for the teaching profession, with emphasis on the need for a partnership between undergraduate and undergraduate teachers and for the discussion of the challenges related to teacher recognition and valorization policies, explaining the complexity of the processes of teacher education.

Keywords: Initial formation. Teaching. Early childhood education.

\section{RESUMEN}

\section{FORMACIÓN INICIAL PARA LA DOCENCIA EN LA EDUCACIÓN INFANTIL: INDICADORES DE LA PRODUCCIÓN ACADÉMICA}

Este texto discute la formación inicial para la docencia en la Educación Infantil, con el objetivo de analizar indicadores resultantes de producciones académicas recientes sobre la temática. Anclado en supuestos teórico-metodológicos bakhtinianos, el presente estudio se caracteriza por un abordaje cualitativo de carácter exploratorio. Para la producción de datos, se optó por procedimiento de levantamiento bibliográfico en periódicos nacionales. La sistematización de los resultados se constituyó por el cálculo de datos cuantitativos y el análisis de los enunciados expresados en los artículos seleccionados. Esta interlocución evidenció la relevancia de la dimensión personal en la formación para la profesión docente, con destaque para la necesidad de asociación entre docentes de la graduación y los estudiantes y para la discusión de los desafíos vinculados a las políticas de reconocimiento y valorización del profesor, explicitando la complejidad de los procesos de formación docente.

Palabras clave: Formación inicial. Docencia. Educación infantil.

\section{Introdução'}

No contexto educacional brasileiro, a questão da formação de professores assume destaque na pauta da agenda política, intensificando os debates a partir da Lei de Diretrizes e Bases da Educação Nacional (LDBEN) (BRASIL, 1996), em razão de reposicionamentos no dever do Estado com a educação pública. Nesses reposicionamentos, destacamos, em função do escopo deste artigo, a integração da Educação Infantil, como primeira etapa, à Educação Básica, passando a compor esse nível de ensino e, consequentemente, a requerer um quadro funcional habilitado. Nesse contexto, a formação inicial alcança novo patamar de visibilidade institucional em 2006 com a aprovação das Diretrizes Curriculares Nacionais (DCN) (BRASIL, 2006), que consolidam a formação para atuação

1 Demarcando nossa ancoragem em um referencial teórico (BAKHTIN, 2010) em que buscamos conceber a ética como uma expressão que nos coloca responsáveis por cada ato singular de nossas vidas, ressaltamos que a realização do estudo que deu origem ao texto apresentado manteve-se em observância a procedimentos éticos quanto à interlocução com os autores e à elaboração de todo o trabalho. nesse campo no conjunto do curso de Pedagogia. ${ }^{2}$

Em meio a inúmeras disputas, quase uma década após a aprovação da Resolução ${ }^{\circ} 01 / 2006$, o Conselho Nacional de Educação (CNE), em cumprimento à Meta 15 do Plano Nacional de Educação (PNE) (BRASIL, 2014), estabelece novas diretrizes para a formação de professores da Educação Básica com a publicação da Resolução $\mathrm{CNE} \mathrm{n}^{\mathrm{o}} 2$, de 1 de julho de 2015, referente às Diretrizes Curriculares Nacionais para a formação inicial em nível superior (cursos de licenciatura, cursos de formação pedagógica para graduados e cursos de segunda licenciatura) e para a formação continuada (BRASIL, 2015b).

Essa normativa agrega novas questões à discussão da formação de professores, destacando a perspectiva de vinculação entre a formação inicial e a formação continuada e a importância

2 Anteriormente, a formação inicial para atuação na Educação Infantil também poderia se efetivar no curso de Pedagogia, todavia, em habilitação específica, cursada somente por alunos(as) que optassem por tal formação. 
do reconhecimento dos processos de valorização profissional. Em meio à implementação dessa normativa (BRASIL, 2017a), ${ }^{3}$ cabe mencionar que o Ministério da Educação lançou a "Política Nacional de Formação de Professores" (BRASIL, 2017b), ${ }^{4}$ tendo várias associações, sindicatos e instituições manifestando seu repúdio às assertivas presentes nessa iniciativa (ASSOCIAÇÃO NACIONAL DE PÓS-GRADUAÇÃO E PESQUISA EM EDUCAÇÃO, 2017; AVALIAÇÃO EDUCACIONAL, 2017; CONFEDERAÇÃO NACIONAL DOS TRABALHADORES EM EDUCAÇÃO, 2017).

Na pauta das discussões em curso, consideramos a temática da formação inicial para a docência na primeira etapa da Educação Básica em um contexto que requer intensas mobilizações em defesa do atendimento com qualidade às crianças de zero a seis anos. ${ }^{5}$ No cenário desses debates, nos inserimos na teia dialógica que problematiza o processo de formação de professores, em especial no que se refere ao reconhecimento da especificidade do trabalho educativo com as crianças pequenas.

Nessa direção, o presente texto integra uma pesquisa coletiva que vem sendo desenvolvida numa abordagem qualitativa de caráter exploratório, com ancoragem em referenciais teórico-metodológicos bakhtinianos, focalizando a formação inicial de professores para a Educação Infantil no contexto das políticas públicas brasileiras. Nesse intento, a pesquisa desenvolve, articuladamente, três metas de ação referentes à abordagem dos ordenamentos legais, das discursividades decorrentes da produção acadêmica e do desenvolvimento das iniciativas públicas de formação, em especial com o propósito de produção de dados junto a estudantes do curso de Pedagogia.

Essa arquitetônica de pesquisa está situada no campo das políticas, observando que, como hoje se encontra estabelecida, a licenciatura no curso de Pedagogia abarca, mais diretamente, a formação para a docência (no campo da Educação Infantil e anos

3 Inicialmente o prazo de adaptação à resolução estava previsto para o ano de 2017 (BRASIL, 2015), sendo alterado pela Resolução $\mathrm{CNE} \mathrm{n}^{\circ}$ 1/2017 para o ano de 2018 (BRASIL, 2017a).

4 Sistematizada para a sociedade em um conjunto de slides.

5 Consideramos a faixa etária da Educação Infantil de zero a seis anos, tendo em vista o previsto na Resolução MEC/SEB $n^{\circ}$ 5/2009 (BRASIL, 2009), que fixa a data corte de 31 de março para matrícula conforme a idade, o que implica o atendimento de crianças nessa faixa etária de seis anos no decorrer dos meses seguintes à data corte. iniciais do Ensino Fundamental) e para a gestão dos processos de ensino, sendo que "[...] um dos maiores desafios que os cursos de pedagogia ainda enfrentam é aprofundar a formação sobre saberes e práticas da docência para crianças" (LUCE, 2017, p. 198).

Assumindo responsivamente nosso lugar nesses debates, para este artigo apresentamos a interlocução com estudos mais recentes, visando compreender os indicadores emergentes que pautam a produção acadêmica na temática da formação inicial para a docência na Educação Infantil. No propósito de abordar a atualidade da discussão, selecionamos produções de pesquisadores brasileiros que, com distintas perspectivas e abordagens, inserem o tema no cenário nacional.

Para comunicar esse estudo, além da introdução e das considerações finais, organizamos este artigo em três movimentos. Assim, logo após esta introdução, como primeiro movimento, descrevemos os caminhos trilhados na abordagem ao campo de produção acadêmica, situando a dinâmica de levantamento dos trabalhos, indicando as opções metodológicas de busca, os descritores utilizados, os critérios definidos e caracterizando cada uma das etapas dessa ação.

Na sequência, apresentamos o quantitativo de trabalhos apurados nos bancos de dados dos periódicos definidos, descrevendo ações que compõem a trajetória de desenvolvimento do estudo.

No terceiro movimento, como percurso exploratório preliminar que antecede nosso recorte temporal de levantamento bibliográfico, realizamos uma aproximação aos estudos da área através da pesquisa de Gatti (2014). Ainda nesse mesmo movimento, compartilhamos a interlocução com as 20 produções selecionadas, dialogando com as ideias expressas pelos autores conforme sua aproximação com a formação inicial e com a docência na Educação Infantil.

Finalizando o texto, sem, contudo, intentar encerrar os diálogos, destacamos as considerações finais, ressaltando as questões primordiais que emergiram com os investimentos analíticos, buscando evidenciar indicadores que situam essa cadeia discursiva. E nesse processo de interação com a palavra-alheia, indicamos a localização e relevância deste estudo, explorando, a seguir, sua trajetória. 


\section{Caminhos trilhados na abordagem da produção acadêmica}

A partir do referencial bakhtiniano (BAKHTIN, 2006, 2011) destacamos nosso pressuposto de que, nos temas em que tomamos como pauta, entramos numa cadeia dialógica, interagindo com muitos já ditos, com dizeres em simultaneidade e com inúmeras outras perspectivas de novos dizeres, abarcando também reiterações, associações, reafirmações e, ainda, desdizeres e silenciamentos. Então, iniciamos assinalando que o processo de busca das produções apresentadas nesse tópico possibilitou o contato de nossos enunciados com enunciados antecedentes, e a narrativa desse contato permitirá o encontro com outros interessados na temática da formação inicial de professores para o campo da Educação Infantil. Assim, situando este artigo como mais um elo que nutre essa cadeia temática e que almeja instar novas produções, nos posicionamos, simultaneamente, como ouvintes e falantes, entendendo que "[...] cada enunciado é um elo na corrente complexamente organizada de outros enunciados" (BAKHTIN, 2011, p. 272).

Nesse escopo teórico, buscamos a dialogia com a produção da área desenvolvendo as primeiras aproximações ao campo com buscas exploratórias nos seguintes bancos de dados: a Biblioteca Digital de Teses e Dissertações (BDTD) - por regiões brasileiras; a Associação Nacional pela Formação dos Profissionais da Educação (ANFOPE); a Associação Nacional de Pós-Graduação e Pesquisa em Educação (ANPEd) - por Grupos de Trabalhos (GT), em especial nos grupos 07 e 08; a Coordenação de Aperfeiçoamento de Pessoal de Nível Superior (CAPES); e Periódicos com estrato indicativo de qualidade A1. Essa busca inicial foi significativa no sentido de perceber as tendências das produções e direcionar as decisões acerca dos bancos de dados mais adequados e dos descritores a serem utilizados na sequência de levantamento dos trabalhos.

As análises desenvolvidas com essa etapa exploratória impulsionaram diferentes problematizações sobre a temática e sobre as opções quanto aos bancos de dados para essa interlocução com a literatura. No conjunto de questionamentos as- sociados à continuidade do trabalho de pesquisa, definimos como recorte temporal o período de 2015 a 2017, significando a data inicial no argumento de ser o ano de publicação das novas DCN (BRASIL, 2015b) e no propósito de buscar os indicadores mais emergentes na atualidade da discussão.

Como procedimento metodológico para a seleção dos veículos de divulgação da produção, optamos por um levantamento bibliográfico que concentrasse as buscas em periódicos com estrato A1, A2, B1 e B2. Argumentamos que, ao mantermos na composição de nosso banco de dados estes estratos conforme classificação da CAPES (COORDENAÇÃO DE APERFEIÇOAMENTO DE PESSOAL DE NÍVEL SUPERIOR, 2014), ${ }^{6}$ realçamos o princípio de valorização das distintas produções acadêmicas e consideramos a sua circulação junto a professores e pesquisadores, retratando uma parte considerável da dinâmica de discussões no campo acadêmico. Portanto, buscamos conhecer produções de pesquisadores brasileiros que focalizam a formação inicial de professores para a Educação Infantil, divulgadas em periódicos.

Desse modo, acreditamos que, ao acessarmos os debates em curso, presentes nessas produções, nos inserimos em um movimento dialógico permanente e repleto de diferentes sentidos, concebendo essa experiência discursiva como um processo contínuo de interação com os enunciados dos outros, pois de acordo com Bakhtin (2011, p. 331): "Dois enunciados distantes um do outro, tanto no tempo quanto no espaço, que nada sabem um sobre o outro, no confronto dos sentidos revelam relações dialógicas se entre eles há ao menos alguma convergência de sentidos". Com isso, reiteramos nosso propósito de compor sentidos em interlocução com outros dizeres circulantes sobre essa temática.

No que se refere ao processo vivenciado, desde a elaboração da problemática e a definição dos

6 O sistema PeriódicosQualis Capes afere a qualidade dos artigos e de outros tipos de produção a partir da análise da qualidade dos periódicos científicos. A classificação de periódicos é realizada pelos Coordenadores indicados por seus pares por um período de três anos para as 49 Áreas de Avaliação, que definem critérios próprios de classificação das revistas para cada área. A atualização da lista de Periódicos do Qualis ocorre anualmente e enquadra os títulos dos periódicos em estratos indicativos de qualidade, sendo A1, o mais elevado e na sequência: A2; B1; B2; B3; B4; B5; C (COORDENAÇÃO DE APERFEIÇOAMENTO DE PESSOAL DE NÍVEL SUPERIOR, 2014). 
objetivos, a pesquisa foi realizada coletivamente por um grupo de trabalho composto por graduandos e pós-graduandos. ${ }^{7}$ No curso das ações, a metodologia do estudo foi discutida, registrada em Diário de Campo, sistematizada em etapas com a organização dos dados em tabelas e gráficos, a fim de documentar o percurso e encadear a sequência dos trabalhos.

As discussões se constituíram em valiosos momentos formativos, especialmente diante da necessidade de definição dos critérios de inclusão e exclusão de artigos. Para esses argumentos, foi importante discutir critérios e enunciar posicionamentos, diante da necessidade de escolhas “[...] de indicadores de avaliação quanto à proximidade e ao distanciamento da questão formulada [...]" (VOSGERAU; ROMANOWSKI, 2014, p. 176). Articulando esses movimentos discursivos ao desenvolvimento do trabalho e aos resultados encontrados, esclarecemos que na sequência deste texto, outros elementos do percurso metodológico são explicitados ao compartilharmos a produção e análise dos dados.

\section{Levantamento dos artigos}

Iniciando o processo de levantamento, acessamos todos os periódicos disponíveis na plataforma Sucupira ${ }^{8}$ que poderiam compor nosso banco de dados. Como critérios, dentre os 1491 periódicos, optamos por compor nosso banco de dados com os periódicos disponíveis em meio eletrônico (ou seja, em versão on-line), com publicação em português, direcionados à área da Educação e gratuitos. $\mathrm{O}$ resultado do trabalho de seleção, com base nesses critérios, pode ser visualizado na Tabela 1 .

Tabela 1 - Resultados quantitativos do levantamento geral de periódicos

\section{Levantamento geral de periódicos}

\begin{tabular}{ccc}
\hline ESTRATO & TOTAL & SELECIONADOS \\
\hline A1 & 121 & 18 \\
A2 & 380 & 22 \\
B1 & 565 & 63 \\
B2 & 425 & 143 \\
\hline Total geral & $\mathbf{1 4 9 1}$ & $\mathbf{2 4 6}$ \\
\hline
\end{tabular}

Fonte: Elaborada pelas autoras deste artigo.

Como podemos constatar, no conjunto de 1491 periódicos registrados na plataforma Sucupira, apuramos um quantitativo de 246 periódicos (16\%) que se tornaram parte do levantamento, com o propósito de pesquisar em suas edições os artigos no escopo temático da formação inicial de professores para a Educação Infantil. Como detalhamento, cabe realçar que desse quantitativo selecionado, os periódicos de estrato B2 têm maior quantidade, com 143 (58\%) e os classifi-

7 O Grupo de Pesquisa Formação e Atuação de Educadores (GRUFAE), constituído a partir de 2006, integra estudantes de graduação (vinculados ao Programa de Educação Tutorial: Projeto Educação) e de Pós-Graduação. No escopo temático, vinculado à atuação e à formação inicial e continuada de docentes, focaliza o campo da Educação Infantil, trabalhando na perspectiva de conhecer o cenário local em interconexão com o contexto ampliado da produção em educação. cados como A1 concentram o menor número de periódicos pertinentes aos nossos critérios, com 18 registros $(0,07 \%)$. Mantendo essa correlação, observamos que, mesmo em números absolutos, essa diferença se mantém, porém o maior quantitativo encontra-se nos periódicos classificados como B1 e o menor continua localizado nos periódicos com estrato A1, confirmando as regras estabelecidas em julho de 2012 acerca de "[...] novos critérios para o Qualis-Periódicos seguindo as

8 A Plataforma é uma nova e importante ferramenta para coletar informações, realizar análises e avaliações e ser a base de referência do Sistema Nacional de Pós-Graduação (SNPG). Deve disponibilizar em tempo real e com muito mais transparência as informações, processos e procedimentos que a CAPES realiza no SNPG para toda a comunidade acadêmica (COORDENAÇÃO DE APERFEIÇOAMENTO DE PESSOAL DE NÍVEL SUPERIOR, 2014). 
diretrizes da Comissão de estudos sobre o Qualis, formada no $1^{\circ}$ Seminário de Acompanhamento da Área (novembro de 2011)" (COORDENAÇÃO DE APERFEIÇOAMENTO DE PESSOAL DE NÍVEL SUPERIOR, 2012, p. 1). Essas regras, reafirmadas em classificações subsequentes, determinam que o somatório de artigos classificados como A1 e A2 alcancem, no máximo, 25\% do total de periódicos no Qualis.

Nos limites deste artigo não abordaremos a vasta problematização referente à organização dos estratos avaliativos; esclarecemos que utilizamos essa métrica apenas para analisar a distribuição em nosso quantitativo selecionado. Avançamos na sequência do trabalho, em que prosseguimos para a segunda etapa, destinada à seleção dos artigos de cada um dos 246 periódicos em todas as suas edições no período de 2015 a 2017. Para essa atividade, contamos com um coletivo de trabalho formado por pequenos grupos, distribuindo a quantidade de periódicos por estrato entre esses grupos. Utilizamos, no sítio eletrônico dos periódicos, a opção "pesquisar" e trabalhamos com os descritores previamente estabelecidos (Formação Inicial/Pedagogia; Currículo/Pedagogia; Projeto Pedagógico; Diretrizes/Pedagogia; Docência/Educação Infantil), com agrupamentos, combinações e variações de alguns descritores para assegurar que os artigos pesquisados atendessem aos objetivos da busca.

No desenvolvimento do trabalho nessa segunda etapa, a localização ocorreu de maneira sistemática na página do periódico, digitando primeiramente $\mathrm{o}$ descritor no campo de "pesquisa". Os títulos informados foram inseridos diretamente em uma tabela, mesmo que, numa análise preliminar, parecessem não corresponder ao escopo da pesquisa. No caso de não localização de artigos com os descritores principais, utilizou-se variações, conforme as previamente estabelecidas. Ao final dessa segunda etapa, chegamos ao quantitativo de 170 artigos, selecionados em função da aplicação dos descritores.

Avançando então para a terceira etapa, já com os títulos dos artigos organizados em quadros relacionando os autores, os periódicos, os links e o período de publicação, procedemos à análise mais aproximada, selecionando aqueles que, efetivamente, dialogassem com a temática da pesquisa de acordo com os títulos.

Essa etapa se fez necessária em decorrência de a aplicação dos descritores utilizados nos permitir localizar artigos com alguma vinculação (das mais tênues às mais vigorosas) à nossa temática de pesquisa, restando a necessidade de avançar na análise para localizar aqueles próprios do escopo em seleção. Para além da forma de organização dos títulos que podem ser “[...] curtos, longos, densos, subjetivos [...] acompanhados por interrogações, e até por reticências" (FERREIRA, 2002), as análises foram dialogadas nos grupos de trabalho, na perspectiva de manter especificamente aqueles que abordavam temáticas ligadas à formação inicial em Pedagogia, recortando, como já assinalamos anteriormente, o foco na formação de professores para atuar na Educação Infantil.

Como resultado desse movimento analítico, do total de 260 artigos inicialmente localizados, selecionamos 20 que se articulam ao escopo do estudo proposto, como podemos visualizar na Tabela 2 .

Tabela 2 - Artigos localizados e selecionados nos periódicos

\begin{tabular}{ccc}
\hline $\begin{array}{c}\text { Periódicos } \\
\text { selecionados }\end{array}$ & $\begin{array}{c}\text { Artigos localizados através do sistema eletrônico } \\
\text { de busca (sites dos periódicos) }\end{array}$ & $\begin{array}{c}\text { Artigos selecionados } \\
\text { (análise dos títulos) }\end{array}$ \\
\hline A1(18) & 47 & 02 \\
\hline A2(22) & 18 & 02 \\
B1(63) & 94 & 04 \\
B2(143) & 101 & 12 \\
& TOTAL & 20 \\
\hline $\mathbf{2 4 6}$ & 260 & 2 \\
\hline
\end{tabular}

Fonte: Elaborada pelas autoras deste artigo. 
Com esse panorama, inferimos que a temática da formação inicial em pedagogia com foco na docência na Educação Infantil ainda é um tema com pouca circulação nos periódicos da área, o que fortalece o propósito da pesquisa proposta. Na apuração desse quantitativo cabe retomar os descritores aplicados, observando que os mais gerais (Formação Inicial/Pedagogia; Currículo/Pedagogia; Projeto Pedagógico; Diretrizes/Pedagogia) permitiam apurar quantitativos mais ampliados que, quando cotejados com os descritores mais específicos (tais como Docência/Educação Infantil), reduziam esse quantitativo. Ainda que incipientes, vale observar a presença da temática em periódicos pertencentes aos vários estratos de avaliação.

Na sequência, como quarta etapa do trabalho, avançamos para o próximo tópico, em que apresentamos uma síntese desse diálogo com os 20 artigos selecionados, explorando os resumos com o propósito de dialogar com os objetivos, metodologias, resultados e conclusões apresentados pela produção selecionada.

\section{As produções acadêmicas em diálogo}

Considerando que o referencial bakhtiniano aponta a importância do contexto das questões em discussão, antes de iniciarmos o movimento dialógico com os artigos selecionados, consideramos importante explorar a publicação de Gatti (2014), compondo um panorama da temática que abordamos. Nessa produção, a autora assinala a relação complexa entre pesquisa e políticas educacionais e apresenta uma síntese do estado do conhecimento sobre formação inicial de professores nos cursos de graduação. $\mathrm{O}$ artigo aborda pesquisas e ensaios relevantes sobre o tema, discute os aspectos que recorrentemente emergem nesses trabalhos e, dentre eles, assinala a questão do isolamento de diretrizes curriculares por curso.

A autora destaca trabalhos que permitem ter um panorama geral atual sobre o cenário dos professores, sua formação inicial e continuada, e da profissão docente no Brasil, citando os estudos produzidos por Gatti e Barretto (2009) e por Gatti, Barretto e André (2011). Segundo a mesma autora, o estudo de Gatti e Barretto (2009) focaliza a constituição da profissionalização docente, abrangendo inúmeros de seus aspectos intervenientes, que se fundamentam em pesquisas direcionadas à legislação que estrutura sua formação, a características e currículos da formação inicial (presencial e à distância), aos modelos especiais de formação implementados por administrações públicas, ao perfil dos professores e dos licenciandos, a aspectos relativos à educação continuada nas redes de ensino, bem como a dados sobre salário e a questões relacionadas às carreiras docentes.

Quanto às políticas no campo da educação, segundo Gatti (2014), conta-se com o estado da arte elaborado, na sequência do estudo anterior, por Gatti, Barretto e André (2011), em que se analisam os caminhos dessas políticas em âmbito nacional e regional, mapeando as políticas relativas à formação inicial e continuada, à carreira e avaliação de docentes e aos subsídios ao trabalho docente visando à melhoria do desempenho escolar dos alunos. Gatti (2014) também ressalta que as sinopses de dados produzidas pelo Instituto Nacional de Estudos e Pesquisas Educacionais (INEP) contribuem para o dimensionamento de inúmeras questões e são utilizadas em vários dos estudos citados, assinalando as contribuições da Associação Nacional pela Formação dos Profissionais da Educação (ANFOPE) e dos estudos encomendados pelo GT "Formação de Professores" da ANPEd.

Ainda de acordo com a autora, os estudos de André $(2009,2010)$ apontam o crescimento do número de pesquisas sobre formação de professores. Tomando por base os trabalhos que André desenvolveu sobre a produção acadêmica em mestrados e doutorados na área de educação, evidenciou-se que, na década de 1990, “[...] o volume proporcional de dissertações e teses da área de educação que tinham como foco a formação de professores girava em torno de 7\%; e, em 2007, esse percentual atinge $22 \%$ dos estudos" (GATTI, 2014, p. 28-29). Recuperamos parcialmente esse panorama elaborado por Gatti (2014) para enfatizar nosso reconhecimento da importância de pesquisas antecedentes à constituição deste estudo e que se inserem nas dinâmicas investigativas, ativando debates acerca do tema da formação inicial. Integrando essa dialogia, seguimos compartilhando nossos resultados com o levantamento desenvolvido. 
Investindo em um movimento dialógico que ampliasse nossa apropriação das produções circulantes no meio acadêmico, na temática da pesquisa em questão, optamos pelo levantamento de dados e suas análises, buscando chegar a outras palavras, outros sentidos acerca da formação inicial para a docência na Educação Infantil no curso de Pedagogia. Em conexão com essa premissa de diálogo com os textos, postulamos a necessidade de que:

Eu devo entrar em empatia com esse outro indivíduo, ver axiologicamente o mundo de dentro dele tal qual ele o vê, colocar-me no lugar dele e, depois de ter retornado ao meu lugar, completar o horizonte dele com o excedente de visão que desse meu lugar se descortina fora dele, convertê-lo, criar para ele um ambiente concludente a partir desse excedente da minha visão, do meu conhecimento, da minha vontade e do meu sentimento. (BAKHTIN, 2011, p. 23).

Nesse contato com os enunciados expressos sobre a formação inicial, com vistas à docência na Educação Infantil, buscamos encontrar, nos diferentes pontos de vista, algumas conexões nos artigos que podem ser percebidas "[...] a partir do mesmo suporte material que os abriga, pela opção teórica manifesta, pelo tema que anunciam, pelo objetivo explicitado da pesquisa, pelo procedimento metodológico adotado pelo pesquisador" (FERREIRA, 2002, p. 266). Nessa perspectiva, elencamos quatro eixos básicos de interlocução com os 20 artigos selecionados, focalizando os objetivos definidos, as opções metodológicas e os resultados evidenciados, os quais compartilhamos a seguir.

3.1 Os objetivos definidos para os estudos

Ao focalizarmos os objetivos expressos, evidenciamos que as aproximações entre os trabalhos publicados nos remetem a quatro eixos de análise que, por variados caminhos, se dirigem também à Educação Infantil: as diretrizes curriculares do curso de Pedagogia (DOURADO, 2015; MASCARENHAS; FRANCO, 2017); a formação inicial de professores numa perspectiva curricular (FAHEINA; ALVES, 2017; FREITAS; MASETTO; FELDMANN, 2016; KELLER-FRANCO; BESSA, 2017; MACHADO, 2016); a formação inicial baseada em marcos legais (KELLER-FRANCO, MASETTO, 2017; NASCIMENTO; CAVALCANTE, 2017; NASCIMENTO; LIRA, 2017; OLI-
VEIRA; ANDRADE, 2017; SILVA; OLIVEIRA, 2017; STANGHERLIM; VERCELLI; SANTOS, 2015) e as vivências pessoais na formação inicial de professores (CHALUH, 2017; CÔCO; GALDINO; VIEIRA, 2016, 2017; GOMES, 2017; MARQUEZAN; SCREMIN; SANTOS, 2017; PEREZ; OLIVEIRA, 2015; SAMPAIO; STOBÄUS, 2017; SANTOS et al, 2016).

Nesse foco, dois textos (DOURADO, 2015; MASCARENHAS; FRANCO, 2017) objetivam uma abordagem mais direta acerca das diretrizes curriculares para o curso de Pedagogia. Um deles focaliza a Resolução CNE/CP n ${ }^{\circ}$ 01/2006 (BRASIL, 2006) e se dedica a discutir a estrutura curricular imposta por essas diretrizes aos processos de formação vivenciados pelos pedagogos na organização curricular dos cursos analisados. O outro se refere à Resolução CNE/CP n ${ }^{\circ}$ 02/2015 (BRASIL, 2015b), apresentando as novas diretrizes curriculares nacionais para a formação inicial e continuada dos profissionais do magistério da Educação Básica, tendo por base o Parecer CNE/ CP n ${ }^{\circ}$ 02/2015 (BRASIL, 2015a).

Direcionados à discussão sobre a formação inicial de professores numa perspectiva curricular, agrupamos quatro textos (FAHEINA; ALVES, 2017; FREITAS; MASETTO; FELDMANN, 2016; KELLER-FRANCO; BESSA, 2017; MACHADO, 2016) que apresentam reflexões sobre as contribuições do currículo integrado para a formação inicial de professores com a intenção de aprofundar sua concepção e avançar em perspectivas curriculares mais condizentes com o contexto educacional atual, além de compreender os laços constituídos entre a formação inicial recebida e a atuação dos estudantes como pedagogos, sobretudo atuantes na área da docência. Desses, dois estudos são relativos ao Programa Institucional de Bolsa de Iniciação à Docência (PIBID).

Situados em questões que envolvem a legislação brasileira que regulamenta a formação inicial expressa pelo PNE, pelas diretrizes curriculares para os cursos de pedagogia e por outros marcos legais, encontramos seis textos (KELLER-FRANCO, MASETTO, 2017; NASCIMENTO; CAVALCANTE, 2017; NASCIMENTO; LIRA, 2017; OLIVEIRA; ANDRADE, 2017; SILVA; OLIVEIRA, 2017; STANGHERLIM; VERCELLI; SANTOS, 
2015) com algumas singularidades presentes em suas aproximações. Enquanto um dos textos se propõe a analisar o espaço curricular conferido à Educação Infantil, outro tem como objetivo verificar a adequação do curso de Pedagogia às diretivas contidas no PNE quanto à construção de estratégias de formação inicial de professores para a primeira etapa da Educação Básica. Outros textos têm como propósito analisar a organização curricular direcionada à formação docente para a Educação Infantil em cursos de licenciatura em Pedagogia e compreender os sentidos e significados da elaboração de seus próprios projetos de currículo, considerando as DCN, além de também explicitar os marcos legais orientadores da formação de professores da Educação Infantil, problematizando a docência com crianças pequenas.

Na exploração desse material selecionado, cabe ressaltar que cinco entre os seis textos focalizam contextos universitários brasileiros, sendo que três declaram se tratar de universidades públicas. Nesse conjunto, ainda consideramos a aproximação explícita de quatro textos à especificidade da docência na Educação Infantil. Nesse sentido, concordamos com Kramer (2005), ao afirmar que:

A formação de profissionais da educação infantil precisa ressaltar a dimensão cultural da vida das crianças e dos adultos com os quais convivem, apontando para a possibilidade de as crianças aprenderem com a história vivida e narrada pelos mais velhos, do mesmo modo que os adultos concebam a criança como sujeito histórico, social e cultural. (KRAMER, 2005, p. 129).

Isso posto, no diálogo com esses objetivos traçados, informando os propósitos que marcam os indicadores mais atuais da discussão sobre a formação inicial, afirmamos que as características do trabalho docente na Educação Infantil particularizam os sentidos relativos à formação, com aspectos bem diferentes das demais etapas da Educação Básica. E esses aspectos precisam ser considerados nos processos de formação inicial.

Com foco em vivências pessoais na formação inicial de professores, os oito textos elencados (CHALUH, 2017; CÔCO; GALDINO; VIEIRA, 2016, 2017; GOMES, 2017; MARQUEZAN; SCREMIN; SANTOS, 2017; PEREZ; OLIVEIRA,
2015; SAMPAIO; STOBÄUS, 2017; SANTOS et al, 2016) se propõem a identificar aproximações e distanciamentos na formação de professores e analisar as práticas de memórias e narrativas como estratégias formativas. Nesse eixo, evidenciam-se como objetivos a aproximação às vivências pessoais e acadêmicas dos licenciandos em Pedagogia, considerando as necessidades de formação e percepções sobre esse processo, as práticas e saberes construídos, as experiências vivenciadas, os desafios e perspectivas de entrada e a permanência na profissão docente.

Em atenção a esses propósitos de estudo manifestos nos artigos, concordamos com Nóvoa (1992), ao afirmar que a formação de professores constitui um momento marcante da configuração profissional, sendo mais do que um processo de aquisição de técnicas e conhecimentos. Portanto, a forma como se delineia a construção da aprendizagem profissional em contexto de formação inicial de professores é primordial na definição do tipo de conhecimentos produzidos e (re) apropriados pelos estudantes, bem como a sua identidade enquanto profissionais.

Na processualidade dessas análises, dialogamos a seguir com questões metodológicas que envolvem os estudos desenvolvidos.

\subsection{Delineamentos metodológicos em questão}

No que se refere à metodologia desenvolvida no encaminhamento dos estudos, em todos os artigos é destacada a abordagem qualitativa, sendo que um trabalho explicita, adicionalmente, o caráter exploratório. Nesse conjunto de 20 textos, quatro não detalham o percurso metodológico no que se refere aos procedimentos e instrumentos, indicando questão já pontuada por André (2001) sobre as dificuldades em desenvolver análises a partir de resumos devido à diversidade das formas de apresentação e ainda à ausência de elementos importantes, havendo textos “"[...] sem informação sobre o tipo de pesquisa e os procedimentos de coleta de dados. Alguns sequer deixavam claro os objetivos do trabalho e vários confundiam metodologia da pesquisa com os procedimentos e instrumentos de pesquisa." (ROMANOWSKI: ENS, 2006, p. 46- 
47). Cabe realçar que, de acordo com Romanowski e Ens (2006), essas limitações foram novamente constatadas em trabalhos desenvolvidos no período de 2003 a 2005, também sob a orientação de André.

Retomando o diálogo com os 16 textos restantes, assinalamos que estes nos permitem apurar um conjunto de procedimentos, com respectivos instrumentos para a produção dos dados, que, reunidos por semelhanças, constituem quatro subgrupos de encaminhamentos metodológicos: os que utilizaram questionários (KELLER-FRANCO; BESSA, 2017; MARQUEZAN; SCREMIN; SANTOS, 2017; SAMPAIO; STOBÄUS, 2017; SANTOS et al, 2016); aqueles que recorreram à análise documental (DOURADO, 2015; FREITAS; MASETTO; FELDMANN, 2016; GOMES, 2017; KELLER-FRANCO, MASETTO, 2017; NASCIMENTO; CAVALCANTE, 2017; NASCIMENTO; LIRA, 2017; OLIVEIRA; ANDRADE, 2017); os que se direcionaram à produção de narrativas (CÔCO; GALDINO; VIEIRA, 2016, 2017); e os que tiveram a combinação de análise documental, questionários e narrativas (FAHEINA; ALVES, 2017; PEREZ; OLIVEIRA, 2015; SANTOS, 2015; STANGHERLIM; VERCELLI).

Esse quadro de opções por procedimentos e instrumentos informa uma articulação entre a abordagem das bases legais e documentos curriculares, em especial por meio da análise documental, e a busca pela interação com vários sujeitos envolvidos nos processos formativos, com destaque para a interlocução com os estudantes em formação. Avançando nas análises, evidenciamos a seguir os resultados e conclusões encaminhados a partir das diferentes abordagens metodológicas.

\subsection{Os resultados e conclusões dos estudos}

No propósito de explorar as conclusões e/ou os resultados expressos pelos autores acerca dos estudos desenvolvidos, buscamos captar nos resumos esses elementos, reiterando que as pesquisas no campo das Ciências Humanas e Sociais, e em especial da educação, têm sua singularidade e, portanto, os resultados precisam ser interpretados nessa perspectiva. Em conexão com o referencial bakhtiniano, assinalamos que, de uma experiência, só podemos tirar indicações ampliando nosso campo de possibilidades.

Com isso, não cabe, nem remotamente, sugerir repetições e possibilidades, sobretudo quando tratamos de processos formativos. Portanto, é importante nos mantermos abertos à escuta de contrapalavras, entendendo que o encontro com as assertivas do outro (implicando concordâncias, discordâncias, adesões, alianças, controvérsias) vivifica o encontro dialógico, movendo completudes às reflexões, ainda que sempre de forma inconclusa. Nessa direção de procurar os indicadores emergentes em conclusões, ainda que preliminares, marcamos as possibilidades de diálogo com os resultados dos estudos, compondo quatro eixos de reflexões.

No primeiro eixo, evidenciamos o indicador da importância das relações entre currículo e processo formativo (FREITAS; MASETTO; FELDMANN, 2016; KELLER-FRANCO; BESSA, 2017; KELLER-FRANCO, MASETTO, 2017; MACHADO, 2016). No que tange ao processo de formação do professor, abarcando a abordagem dos saberes e das práticas, o desenvolvimento desse indicador permite apurar a proposta do currículo integrado como uma alternativa para a renovação do paradigma curricular tradicional, a fundamentação em projetos como possibilidade de romper com o paradigma técnico disciplinar, a demanda pela ressignificação da formação inicial de professores e a importância da interação entre instituições e sujeitos envolvidos no processo.

No segundo eixo, o indicador nos permite assinalar a relevância da dimensão pessoal na formação para a profissão docente (CHALUH, 2017; CÔCO; GALDINO; VIEIRA, 2016), ressaltando tanto o reconhecimento da subjetividade nos processos formativos como diferencial na qualidade de educação, como a necessidade de vivificar reflexões sobre as aprendizagens pessoais e os desafios da educação, sobretudo com as crianças pequenas. Nessa perspectiva, Côco (2013, p. 193, grifo nosso) afirma que:

[...] nós, que não frequentamos a EI [Educação Infantil], transportamos uma memória da estrutura da escola para o trabalho com as crianças pequenas. Uma compreensão fortalecida pelos processos de formação inicial, geralmente, mais voltados ao trabalho no Ensino Fundamental. 
Nesse sentido, advoga-se que os processos formativos precisam abrir espaços para mover narrativas que possibilitem analisar o campo de trabalho na Educação Infantil, num movimento de instar posicionamentos na abordagem a esse campo. Em resumo, dizer da Educação Infantil, se dizendo nela.

E para isso, acreditamos na necessidade de ter ousadia para desenvolver processos formativos que busquem escapar de modelos padronizados (PINAZZA, 2014), além de "[...] edificar um novo lugar para a formação de professores, numa zona de fronteira entre a universidade e as escolas" (NÓVOA, 2017, p. 1115), reafirmando a dimensão coletiva da formação e do trabalho docente.

Atinentes a essa dimensão coletiva, no terceiro eixo, o indicador apurado circunscreve a defesa de que o lócus da formação docente é a própria Pedagogia, enquanto campo científico, requerendo a parceria entre docentes da graduação e seus alunos na composição do processo educativo comum. Nesse lócus, os estudos retratam ainda experiências no desenvolvimento dos estágios supervisionados e do PIBID, focalizam as (des)articulações entre teoria e prática, as implicações dos processos formativos na construção de uma identidade profissional, os desafios pessoais e acadêmicos que interagem com o desenvolvimento da formação e a observação da instabilidade e desvalorização profissional presente no campo de trabalho (MARQUEZAN; SCREMIN; SANTOS, 2017; PEREZ; OLIVEIRA, 2015; SAMPAIO; STOBÄUS, 2017).

Podemos evidenciar que esse eixo destaca uma concepção de formação inicial que se fundamenta em práticas reconhecidas como importantes e significativas para o exercício da docência, entendendo a formação como um processo que associa a formação inicial ao direito à formação continuada, afirmando o desenvolvimento profissional (NÓVOA, 2004).

Seguindo para o quarto eixo, o indicador retrata alguns desafios colocados às atuais políticas de valorização do professor, explicitando a complexidade envolvida nos processos de formação e de encaminhamento da prática docente (DOURADO, 2015; GOMES, 2017; MASCARENHAS; FRANCO, 2017; NASCIMENTO; CAVALCANTE, 2017; NASCIMENTO; LIRA, 2017; OLIVEIRA;
ANDRADE, 2017; SANTOS et al, 2016; STANGHERLIM; VERCELLI; SANTOS, 2015). De maneira geral, as conclusões indicam, no caso do Brasil, a formação genérica e pouco especializada, não respondendo a contento às demandas para a atuação com crianças pequenas em ambientes institucionais. Nesse sentido, retomamos o conceito de formação inicial proposto por Cunha (2013, p. 612): "Por formação inicial entendem-se os processos institucionais de formação de uma profissão que geram a licença para o seu exercício e o seu reconhecimento legal e público".

Quando enfocamos a formação inicial de professores para a Educação Infantil, cabe observar que a licença de atuação precisa responder às peculiaridades exigidas pela docência na atuação na primeira etapa da Educação Básica. Os estudos retratam contribuições e investimentos encaminhados em determinados contextos e também insuficiências, controvérsias e fragilidades que assolam a formação inicial, instando as diretrizes curriculares para o curso de Pedagogia no enfrentamento das dificuldades de estruturação dos cursos de formação.

A composição desses quatro eixos de indicadores das discussões mais atuais sobre a formação de professores para a Educação Infantil, circulantes por meio de periódicos, se situa no contexto das exigências que se acenam no horizonte do curso de Pedagogia para as Instituições de Ensino Superior (IES) com as novas DCN. Reconhecemos que os profissionais e estudantes se veem diante de significativas alterações no processo de formação inicial, participando da história de outras mudanças no curso, num contexto em que emergem novos desafios. Essas alterações dialogam ainda com as movimentações do campo de trabalho que, assinalando indicadores e encaminhando iniciativas de ação, também impactam os processos formativos em desenvolvimento nas instituições de formação inicial. Nesse aspecto importa lembrar que os processos de precarização do trabalho docente têm afetado, mais consistentemente, o contexto da Educação Infantil (FERREIRA; CÔCO, 2011).

$\mathrm{Na}$ especificidade da implementação das diretrizes do curso de Pedagogia, nos eixos compostos, é possível ainda criar um subgrupo com alguns estudos (CÔCO; GALDINO; VIEIRA, 2017; FAHEINA; ALVES, 2017; SILVA; OLIVEIRA, 
2017) que, nessa abordagem, informam sobre as negociações envolvidas no processo de implementação das diretrizes, os desafios na articulação entre a identidade do curso e a proposta das DCN, as contribuições do curso de Pedagogia na afirmação da formação docente para o campo da Educação Infantil e a importância de considerar as perspectivas de atuação profissional acenadas pelo campo de trabalho no bojo do reconhecimento da Educação Infantil como primeira etapa da Educação Básica.

Assim, concluindo esse tópico voltado ao diálogo com as produções, com o referencial bakhtiniano, assinalamos um conjunto de indicadores que compõem a abordagem da formação inicial de professores para atuação na Educação Infantil. Na composição dos estudos, observando os objetivos propostos, os encaminhamentos metodológicos, bem como os resultados afirmados, por um lado, podemos assinalar que esses indicadores não apresentam novidades nas discussões sobre a formação de maneira mais geral. Entretanto, por outro lado, quando esses indicadores são situados no contexto da Educação Infantil, novas nuanças emergem, indicando que sua especificidade insta demandas próprias aos processos formativos. $\mathrm{Ou}$ seja, a atuação com crianças pequenas informa uma pedagogia própria (ROCHA, 1999), que precisa ser realçada nos processos formativos como mecanismo de fortalecimento de suas diretrizes curriculares (BRASIL, 2009).

\section{Considerações finais}

Conforme viemos encaminhando, neste artigo abordamos as reflexões sobre a formação inicial para a docência na Educação Infantil propostas por produções acadêmicas brasileiras, veiculadas em periódicos, numa temporalidade mais recente. Perquirindo a atualidade da discussão, o diálogo com os textos selecionados assinala múltiplos enfoques que expressam uma diversidade de perspectivas.

Reconhecendo o caráter próprio de cada estudo, na circunscrição do foco na Pedagogia, com relação à formação inicial para a docência, mais especificamente na Educação Infantil, emerge o destaque para as diretrizes curriculares que normatizam a organização do curso em cotejamento com sua implementação, evidenciando um conjunto de problemáticas associadas. Problemáticas mais ligadas aos processos internos de desenvolvimento da formação inicial, mas não apartadas dos desafios e demandas presentes no campo de trabalho e das dinâmicas sociais mais amplas.

Situados no contexto político atual, esses desafios exigem ações de fortalecimento da defesa de espaços de interlocução entre os sujeitos envolvidos na ação educativa, tendo em vista o desrespeito às conquistas das últimas décadas no que tange às políticas públicas. Em consonância com o que se encontra expresso nos textos legais e focalizando o campo da educação, faz-se necessário reafirmar os compromissos educacionais com a infância e com a Educação Infantil, considerando os direitos das crianças e de suas famílias à educação de qualidade que pressupõe, entre outros fatores relevantes, a qualidade da formação inicial e continuada de estudantes e profissionais atuantes nas instituições de Educação Infantil.

$\mathrm{Na}$ complexidade envolvida, articulados aos resultados informados pelos estudos, os indicadores apontam para a importância das relações entre o currículo e o processo formativo, evidenciando a relevância da dimensão pessoal na formação para a profissão docente. Assinalam também a defesa da Pedagogia como lócus da formação inicial para atuação na Educação Infantil, ressaltando, na busca por responder aos desafios mais internos do curso, a necessidade de parceria no processo educativo entre docentes e graduandos. Na comunicabilidade com as demandas do campo de trabalho, marcam os desafios postos no quadro das atuais políticas de (des)valorização dos professores.

Na incompletude das análises até então apresentadas, com esses indicadores, ressaltamos alguns elementos presentes na produção acadêmica acerca da formação inicial na Educação Infantil. Nesse sentido, integramos essa teia dialógica reafirmando um posicionamento da defesa da necessidade de problematizar os processos formativos, em especial, considerando os desafios presentes no campo de atuação na Educação Infantil, sem com isso abdicar de advogar que a formação inicial deve ocorrer em curso superior, de licenciatura em Pedagogia, ofertado pelas instituições de ensino superior, que a formação continuada é direito de todos os docentes e que a formação na pós-graduação precisa ser estimulada. 
No reconhecimento de que muito ainda há a dizer sobre os processos de formação de professores, buscando mover outros elos nessa cadeia temática, concluímos convidando os leitores a novas interlocuções, no horizonte de produzir investimentos que fortaleçam a Educação Infantil.

\section{REFERÊNCIAS}

ANDRÉ, M. E. D. A. A pesquisa sobre formação de professores no Brasil - 1990-1998. In: CANDAU, Vera M. (Org.). Ensinar e aprender: sujeitos, saberes e pesquisa. 2. ed. Rio de Janeiro: DP\&A, 2001. p. 83-100.

. A produção acadêmica sobre formação docente: um estudo comparativo das dissertações e teses dos anos 1990 e 2000. Revista Brasileira de Pesquisa sobre Formação de Professores, v. 1, n. 1, p. 41-56, ago./dez. 2009. Disponível em: $<$ http://www.scielo.br/scielo.php?script=sci_nlinks\&ref=000110\&pid=S1413...lng... $>$. Acesso em: 13 mar. 2014.

. Formação de professores: a constituição de um campo de estudos. Educação, Porto Alegre, v. 33, p. 6-18, 2010. Disponível em: <http://revistaseletronicas.pucrs.br/ojs/index.php/faced/article/view/8075>. Acesso em: 13 mar. 2014.

ASSOCIAÇÃO NACIONAL DE PÓS-GRADUAÇÃO E PESQUISA EM EDUCAÇÃO (ANPEd). Manifestação das entidades educacionais sobre a política de formação de professores anunciada pelo MEC. Rio de Janeiro, 2017. Disponível em: <http://www.anped.org.br/news/manifestacao-das-entidades-educacionais-sobre-politica-de-formacao-de-professores-anunciada>. Acesso em: 04 dez. 2017.

AVALIAÇÃO EDUCACIONAL. "Fake policy" na formação de professores. Campinas, SP, 2017. Disponível em: $<$ https://avaliacaoeducacional.com/2017/10/20/fake-policy-na-formacao-de-professores/>. Acesso em: 04 dez. 2017.

BAKHTIN, M. M. Marxismo e filosofia da linguagem. 12. ed. São Paulo: Hucitec, 2006.

Para uma filosofia do ato responsável. Tradução de Valdemir Miotello e Carlos Alberto Faraco. São Carlos, SP: Pedro \& João, 2010.

Estética da criação verbal. 6. ed. São Paulo: Martins Fontes, 2011.

BRASIL. Presidência da República. Casa Civil. Lei n. ${ }^{\circ}$ 9.394, de 20 de dezembro de 1996. Estabelece as diretrizes e bases da educação nacional. Brasília, DF, 1996. Disponível em: <http://www.planalto.gov.br/ccivil_03/Leis/ L9394.htm>. Acesso em: 16 jul. 2013.

Ministério da Educação. Conselho Nacional de Educação. Conselho Pleno. Resolução CNE/CP n. ${ }^{\mathbf{1}}$, de 15 de maio de 2006. Institui as Diretrizes Curriculares Nacionais para o Curso de Graduação em Pedagogia, licenciatura. Brasília, DF, 2006. Disponível em: $<$ http://portal.mec.gov.br/cne/arquivos/pdf/rcp01_06.pdf $>$. Acesso em: 22 abr. 2015.

Ministério da Educação. Conselho Nacional de Educação. Conselho Pleno. Parecer CNE/CP no 2, de 9

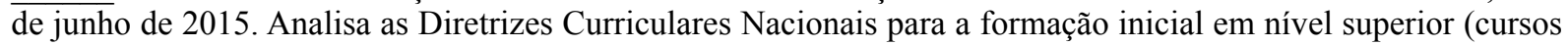
de licenciatura, cursos de formação pedagógica para graduados e cursos de segunda licenciatura) e para a formação continuada. Brasília, DF, 2015a. Disponível em: <http://pronacampo.mec.gov.br/images/pdf/parecer_cne_ cp_2_2015_aprovado_9_junho_2015.pdf $>$. Acesso em: 28 out. 2015.

Ministério da Educação. Conselho Nacional de Educação. Conselho Pleno. Resolução CNE/CP n. 2, de

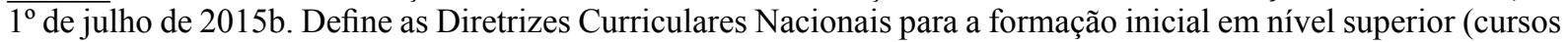
de licenciatura, cursos de formação pedagógica para graduados e cursos de segunda licenciatura) e para a formação continuada. Brasília, DF, 2015b. Disponível em: <http://portal.mec.gov.br/docman/agosto-2017-pdf/70431-res-cnecp-002-03072015-pdf/file>. Acesso em: 28 out. 2015.

Ministério da Educação. Secretaria de Ensino Básico. Resolução MEC/SEB no 05, de 17 de dezembro de 2009. Fixa as diretrizes curriculares nacionais para a Educação Infantil. Brasília, DF, 2009. Disponível em: <http:// portal.mec.gov.br/index.php?option=com_docman\&task>. Acesso em: 16 jul. 2013.

. Presidência da República. Casa Civil. Lei no 13.005, de 25 de junho de 2014. Institui o Plano Nacional de Educação e dá outras providências. Brasília, DF, 2014. Disponível em: <http://www.planalto.gov.br/legislacao>. Acesso em: 27 jun. 2014. 
Ministério da Educação. Conselho Nacional de Educação. Conselho Pleno. Resolução CNE/CP no 1 , de 9 de agosto de 2017. Altera o Art. 22 da Resolução CNE/CP n ${ }^{\circ}$, de $1^{\circ}$ de julho de 2017. Brasília, DF, 2017a. Disponível em: $<$ http://portal.mec.gov.br/index.php?option=com_docman\&view=download\&alias=70141-rcp00117-pdf\&category_slug=agosto-2017-pdf\&Itemid=30192>. Acesso em: 29 nov. 2017.

. Ministério da Educação. Política Nacional da Formação de Professores. Brasília, DF, 2017b. Disponível em: $<$ http://portal.mec.gov.br/index.php?option=com_docman\&view=download\&alias $=74041$-formacao-professor-final-18-10-17-pdf\&category_slug=outubro-2017-pdf\&Itemid=30192>. Acesso em: 4 dez. 2017.

CHALUH, N. L. Da dimensão pessoal na formação inicial de professores. Série-Estudos, Rio Claro, v. 22, n. 44, p.181-200, jan/abr, 2017. Disponível em: <http://www.serie-estudos.ucdb.br/index.php/serie-estudos/article/ view/964>. Acesso em: 23 out. 2017.

CÔCO, V. Conquistas, avanços, desafios e disputas na política de educação infantil: transformações na docência em nós. In: RANGEL, I. S.; NUNES, K. R.; CÔCO, V. (Org.). Educação Infantil: rede de conversações e produções de sentidos com crianças e adultos. Petrópolis, RJ: De Petrus, 2013. p. 181-199.

CÔCO, V.; GALDINO, L.; VIEIRA, M. A. F. O. Narrativas de formação: trabalho com memoriais na aproximação à docência na educação infantil. Revista Cocar, Belém, v. 10, n. 19, p. 121-139, jan./jul. 2016. Disponível em: $<$ https://paginas.uepa.br/seer/index.php/cocar/article/view/788/564>. Acesso em: 23 out. 2017.

. Trajetórias de formação: perspectivas para a docência na Educação Infantil. Revista Espaço do Currículo, João Pessoa, v. 10, n. 2, p. 272-289, maio/ago. 2017. Disponível em: <http://www.okara.ufpb.br/ojs/index.php/rec/ article/view/rec.v10i2.35502/18296>. Acesso em: 23 out. 2017.

COORDENAÇÃO DE APERFEIÇOAMENTO DE PESSOAL DE NÍVEL SUPERIOR (CAPES). Ministério da Educação. Critérios de classificação Qualis - ensino. Brasília, DF, 2012. Disponível em: $<$ https://www.capes.gov. br/images/stories/download/avaliacaotrienal/Docs_de_area/qualis/ensino.pdf $>$. Acesso em> 04 dez. 2017.

. Ministério da Educação. Classificação da produção intelectual. Brasília, DF, 2014. Disponível em: <http:// www.capes.gov.br/avaliacao/instrumentos-de-apoio/classificacao-da-producao-intelectual>. Acesso em: 04 dez. 2017.

CONFEDERAÇÃO NACIONAL DOS TRABALHADORES EM EDUCAÇÃO (CNTE). Nota pública sobre a política nacional de formação de professores do MEC. Brasília, DF, 2017. Disponível em: <http://www.cnte.org. br/index.php/documentos/notas-publicas/19239-politica-nacional-de-formacao-de-professores-mec.html $>$. Acesso em: 04 dez. 2017.

CUNHA, M. I. O tema da formação de professores: trajetórias e tendências do campo na pesquisa e na ação Revista Educação e Pesquisa, São Paulo, n. 3, p. 609-625, jul./set. 2013. Disponível em: <http://www.scielo.br/scielo. php?pid=S1517-97022013000300004\&script $>$.|Acesso em: 19 nov. 2013.

DOURADO, L. F. Diretrizes curriculares nacionais para a formação inicial e continuada dos profissionais do magistério da educação básica: concepções e desafios. Educação \& Sociedade, Campinas, SP, v. 36, n. 131, abr./ jun. 2015. Disponível em: $<$ http://www.scielo.br/scielo.php?script=sci_arttext\&pid=S0101-73302015000200299\&ln $\mathrm{g}=$ pt\&nrm=iso $>$. Acesso em: 23 out. 2017.

FAHEINA, E. F. A.; ALVES, F. T. O. O curso de pedagogia do Vale do Mamanguape no contexto das atuais Diretrizes Curriculares Nacionais. Revista Espaço do Currículo, João Pessoa, v. 10, n. 2, p. 344-355, maio/ago. 2017. Disponível em: $<$ http://www.okara.ufpb.br/ojs/index.php/rec/article/view/rec.v10i2.35588/18289>. Acesso em: 23 out. 2017.

FERREIRA, E. B.; CÔCO, V. Gestão na educação infantil e trabalho docente. Revista Retratos da Escola, Brasília, DF, v. 5, n. 9, p. 357-370, jul./dez. 2011. Disponível em: <http://www.esforce.org.br>. Acesso em: 4 out. 2012.

FERREIRA, N. S. de A. As pesquisas denominadas "estado da arte". Educação \& Sociedade, ano XXIII, n. 79, ago. 2002. Disponível em: <http://www.scielo.br/pdf/es/v23n79/10857.pdf>. Acesso em: 23 abr. 2017.

FREITAS, S. A.; MASETTO, M. T.; FELDMANN, M. G. O currículo no contexto atual: a interface com o trabalho pedagógico. Revista Cocar, Belém, n. 2, p. 53-75, ago./dez. 2016. Edição especial. Disponível em: <https://paginas. uepa.br/seer/index.php/cocar/article/view/999/645>. Acesso em: 23 out. 2017.

GATTI, B. A. Formação inicial de professores para a educação básica: pesquisas e políticas educacionais. Estudos em Avaliação Educacional, São Paulo, v. 25, n. 57, p. 24-54, jan./abr. 2014. Disponível em: <http://www.fcc.org. br/pesquisa/publicacoes/eae/arquivos/1899/1899.pdf>. Acesso em: 15 maio 2017. 
GATTI, B. A.; BARRETTO, E. S. de S. Professores do Brasil: impasses e desafios. Brasília, DF: Unesco, 2009. Disponível em: <http://unesdoc.unesco.org/images/0018/001846/184682por.pdf>. Acesso em: 27 ago. 2013.

GATTI, B. A.; BARRETTO, E. S. de S.; ANDRÉ, M. E. D. A. Políticas docentes no Brasil: um estado da arte. Brasília, DF: Unesco, 2011. Disponível em: <http://unesdoc.unesco.org/images/0021/002121/212183por.pdf>. Acesso em: 27 ago. 2013.

GOMES, M. O. Formação de educadores de infância em Portugal e professores de educação infantil no Brasil: aproximações e distanciamentos. Educação Unisinos, São Leopoldo, RS, v. 21, n. 1, p. 50-59, jan./abr. 2017. Disponível em: <http://revistas.unisinos.br/index.php/educacao/article/view/edu.2017.211.06/5853>. Acesso em: 23 out. 2017.

KELLER-FRANCO, E.; BESSA, S. Construindo alternativas para a formação inicial de professores: a percepção de estudantes de pedagogia sobre a abordagem curricular integrada. Revista e-Curriculum, São Paulo, v. 15, n. 1, p. 153-176, jan./mar. 2017. Disponível em: <https://revistas.pucsp.br/index.php/curriculum/article/view/26097/22382>. Acesso em: 23 out. 2017.

KELLER-FRANCO, E.; MASETTO, M. T. Avanços curriculares na formação inicial de professores. Revista Contrapontos - Eletrônica, Itajaí, SC, v. 17, n. 3, p. 529-551, jul./set. 2017. Disponível em: <https://siaiap32.univali. br/seer/index.php/rc/article/view/9780/pdf>. Acesso em: 23 out. 2017.

KRAMER, S. Profissionais de educação infantil - gestão e formação. São Paulo: Ática, 2005.

LUCE, Maria Beatriz. Formação de professores: a política e as diretrizes curriculares. Entrevistada por Fernanda Borges de Andrade. Em Aberto, Brasília, DF, v. 30, n. 98, p. 185-200, jan./abr. 2017. Disponível em: <http://emaberto.inep.gov.br/index.php/emaberto/article/view/3187>. Acesso em: 18 out. 2017.

MACHADO, L. C. (Re)configuração curricular no processo de formação de professores e suas relações. Educação, Santa Maria, RS, v. 41, n. 2, p. 297-309, maio/ago. 2016. Disponível em: <https://periodicos.ufsm.br/reveducacao/ article/view/15079/pdf>. Acesso em: 23 out. 2017.

MARQUEZAN, F. F.; SCREMIN, G.; SANTOS, E. A. G. Aprendizagem da docência na formação inicial de professores: contribuições do Pibid/Pedagogia. Educação por Escrito, Porto Alegre, v. 8, n. 1, p. 112-128, jan./ jun. 2017. Disponível em: $<$ http://revistaseletronicas.pucrs.br/ojs/index.php/porescrito/article/view/26020/15734>. Acesso em: 23 out. 2017.

MASCARENHAS, A. D. N.; FRANCO, M. A. S. De pedagogos a professores: balanço de uma década das Diretrizes Curriculares dos Cursos de Pedagogia no Brasil. Revista Internacional de Formação de Professores (RIFP), Itapetininga, SP, v. 2, n. 1, p. 41-55, 2017. Disponível em: < http://itp.ifsp.edu.br/ojs/index.php/RIFP/article/ view/634>. Acesso em: 23 out. 2017.

NASCIMENTO, L. F.; CAVALCANTE, M. M. D. Formação docente para a educação infantil: uma leitura do curso de pedagogia pós diretrizes curriculares. Revista Contrapontos - Eletrônica, Itajaí, SC, v. 17, n. 3, p. 552-574, jul./set. 2017. Disponível em: <https://siaiap32.univali.br/seer/index.php/rc/article/view/9532/pdf>. Acesso em: 23 out. 2017.

NASCIMENTO, S. M. B.; LIRA, A. C. M. Marcos legais para a formação de professores da educação infantil e desafios à docência. Zero-a-Seis, Florianópolis, v. 19, n. 35, p. 99-116, jan./jun. 2017. Disponível em: <https:// periodicos.ufsc.br/index.php/zeroseis/article/view/1980-4512.2017v19n35p99>. Acesso em: 23 out. 2017.

NÓVOA, A. Comunicação do representante da Sociedade Portuguesa de Ciências da Educação no XIII Congresso do MEM em Lisboa. In: VILHENA, G.; SOARES, J.; HENRIQUE, M. (Org.). Nos 25 anos do movimento da escola moderna portuguesa. Lisboa: MEM, 1992. Disponível em: <http:!/www.movimentoescolamoderna.pt!associacao/ opinioesacercado-meml>. Acesso em: 6 jul. 2015.

. Educação e formação ao longo da vida: entrevista. São Paulo: CRE Mario Covas, entrevista concedida por e-mail em out. 2004. Disponível em: <http:www.crmariocovas.sp.gov.br>. Acesso em: 8 ago. 2013.

Firmar a posição como professor, afirmar a profissão docente. Cadernos de Pesquisa, v. 47, n. 166, p. 1106-1133, out./dez. 2017. Disponível em: <http://www.scielo.br/scielo.php?script=sci_abstract\&pid=S0100-15742017000401106\&lng=pt\&nrm=iso>. Acesso em: 12 dez. 2017.

OLIVEIRA, F.; ANDRADE, G. G. O curso de pedagogia nas universidades federais do Estado de Minas Gerais: reflexões acerca do espaço da educação infantil nos currículos de formação inicial. Revista Ibero-Americana de Estudos em Educação - RIAEE, Araraquara, SP, v. 12, n. 1, p. 258-277, 2017. Disponível em: <http://seer.fclar. unesp.br/iberoamericana/article/view/8233/6265>. Acesso em: 23 out. 2017. 
PEREZ, D.; OLIVEIRA, S. O. Formação de professoras no curso de pedagogia: o refletido e o vivido. Comunicações, Piracicaba, SP, v. 22, n. 1, p. 99-118, jan./jun. 2015. Disponível em: < https://www.metodista.br/revistas/ revistas-unimep/index.php/comunicacoes/article/view/2136/1494>. Acesso em: 23 out. 2017.

PINAZZA, M. A. Formação de profissionais da educação infantil em contextos integrados: informes de uma investigação-ação. 2014. 408 f. Tese (Livre docência) - Faculdade de Educação da Universidade de São Paulo (USP), São Paulo, 2014. Disponível em: <http://www.teses.usp.br/teses/disponiveis/livredocencia/48/tde-01122014-155847/ pt-br.php>. Acesso em: 19 jul. 2017.

ROCHA, E. A. C. A pesquisa em Educação Infantil no Brasil: trajetória recente e perspectivas de consolidação de uma pedagogia. 1999. 582 f. Tese (Doutorado em Educação) - Faculdade de Educação da Universidade de Campinas (Unicamp), Campinas, SP, 1999. Disponível em: <http://www.bibliotecadigital.unicamp.br/ document/?code $=$ vtls000184228 $>$. Acesso em: 17 jun. 2013.

ROMANOWSKI, J. P.; ENS. R. T. As pesquisas denominadas do tipo "estado da arte" em educação. Diálogo Educacional, Curitiba, v. 6, n. 19, p. 37-50, set./dez. 2006. Disponível em: <http://www2.pucpr.br/reol/pb/index.php/ dialogo?dd1=237\&dd99=view>. Acesso em: 16 nov. 2017.

SAMPAIO, A. A.; STOBÄUS, C. D. Formação inicial docente: vivências e necessidades percebidas por licenciandos. Revista Contrapontos - Eletrônica, Itajaí, SC, v. 17, n. 1, p. 1-19, jan./abr. 2017. Disponível em: <https://siaiap32. univali.br/seer/index.php/rc/article/view/7708/pdf>. Acesso em: 23 out. 2017.

SANTOS, L. Et al. Formação inicial de professores, Pibid e a opção pela docência. Educação e Linguagem, São Paulo, v. 19, n. 1, p. 97-124, jan./jun. 2016. Disponível em: <https://www.metodista.br/revistas/revistas-metodista/ index.php/EL/article/view/7095/5429>. Acesso em: 23 out. 2017.

SILVA, S. A.; OLIVEIRA, O. V. Entre sentidos e significados da tradução das diretrizes curriculares nacionais de pedagogia (DCNS) em MT. Revista Espaço do Currículo, João Pessoa, v. 10, n. 2, p. 310-326, maio/ago. 2017. Disponível em: <http://www.okara.ufpb.br/ojs/index.php/rec/article/view/rec.v10i2.35460/18298>. Acesso em: 23 out. 2017.

STANGHERLIM, R.; VERCELLI, L. C. A.; SANTOS, E. Plano Nacional de Educação (PNE 2014-2024) e a formação inicial para a docência na educação infantil: análise exploratória de um curso de pedagogia de uma universidade pública paulista. Eccos Revista Científica, São Paulo, n. 37, p. 19-42, maio/ago. 2015. Disponível em: $<$ http://www4.uninove.br/ojs/index.php/eccos/article/view/5785>. Acesso em: 23 out. 2017.

VOSGERAU, D. S. R.; ROMANOWSKI, J. P. Estudos de revisão: implicações conceituais e metodológicas. Revista Diálogo Educacional, Curitiba, v. 14, n. 41, p. 165-189, jan./abr. 2014. Disponível em: <https://periodicos.pucpr. br/index.php/dialogoeducacional/article/view/2317>. Acesso em: 14 abr. 2017. 